\title{
Sées - Étude des moules monétaires de la rue Amesland
}

$\mathrm{n}^{\circ} 3242$

\section{Pierre-Marie Guihard}

\section{(2) OpenEdition \\ Journals}

Édition électronique

URL : http://journals.openedition.org/adlfi/17156

ISSN : 2114-0502

Éditeur

Ministère de la culture

\section{Référence électronique}

Pierre-Marie Guihard, « Sées - Étude des moules monétaires de la rue Amesland », ADLFI. Archéologie de la France - Informations [En ligne], Basse-Normandie, mis en ligne le 23 mars 2016, consulté le 19 avril 2019. URL : http://journals.openedition.org/adlfi/17156

Ce document a été généré automatiquement le 19 avril 2019

(c) Ministère de la Culture et de la Communication, CNRS 


\title{
Sées - Étude des moules monétaires de la rue Amesland
}

$n^{\circ} 3242$

\author{
Pierre-Marie Guihard
}

Lien Atlas (MCC) :

http://atlas.patrimoines.culture.fr/atlas/trunk/index.php?

ap_theme=DOM_2.01.02\&ap_bbox $=0.105 ; 48.570 ; 0.225 ; 48.645$

1 La découverte de moules d'argile à Sées, lors d'opérations de sauvetage conduites par le Service régional de l'archéologie de Basse-Normandie entre 1992 et 1993, atteste l'existence d'une officine ayant produit des bronzes coulés de Domitien, Trajan, Hadrien et Antonin le Pieux. Tous les moules proviennent d'un secteur à forte vocation artisanale situé en bordure septentrionale de l'agglomération antique, au niveau de l'actuelle rue Amesland.

2 L'enquête menée à partir des 77 moules et fragments découverts, conservés aujourd'hui au musée de Normandie, a visé à reconstituer les procédés de fabrication, tout en précisant la phase de production (circa 260), dont la datation s'est appuyée en particulier sur l'étude de la composition des trésors de bronzes du Haut-Empire.

Ce sont vraisemblablement de fortes tensions sur le numéraire de faible valeur au cours $\mathrm{du} \mathrm{III}^{\mathrm{e}}$ siècle qui ont motivé la multiplication frauduleuse d'un monnayage en bronze. Grâce à J.-P. Callu, on connaît bien la circulation du bronze en Occident. En 1969 il en a exposé les grandes lignes, en soulignant que la monnaie de bronze ne jouait plus au $\mathrm{III}^{\mathrm{e}} \mathrm{s}$. le rôle impérial qui avait été le sien au cours du siècle précédent. Elle était devenue une monnaie locale, limitée à l'Italie, à l'Espagne, et à l'Afrique du Nord. Plus on s'éloignait de ces régions et plus les provinces eurent de grandes difficultés à s'approvisionner en bronzes frappés à Rome. En Gaule, tout comme en Bretagne ou encore dans les Germanies, les monnaies de bronze émises après le règne de Commode (180-192) y 
circulaient peu et surtout le stock de ce métal a vu survivre en abondance les émissions des générations passées.

4 Toutefois, le choix des contrefacteurs de Sées de ne surmouler que des bronzes à l'effigie radiée invite tout particulièrement à lier l'activité de l'officine sagienne à la politique monétaire de Postume. En effet, Postume entreprit de réformer le monnayage de bronze au cours de l'année 260 ; réforme qui déboucha sur la création d'un double sesterce arborant une effigie impériale coiffée précisément d'une couronne radiée. Le but était ici de donner à la nouvelle monnaie une valeur supérieure à celle du sesterce traditionnel (et lauré). Pourtant, elle n'était qu'une émission de bronze d'un poids identique ou à peine plus lourd que les espèces laurées antérieures. Le même poids acquérait ainsi une majoration de $100 \%$, ce qui revenait à conférer au double sesterce de Postume une valeur libératoire plus élevée. Si la réforme permit certainement d'élargir un stock en petit numéraire limité au bronze hérité du Haut-Empire, elle se révéla être très vite un échec. En instaurant un change entre bronzes laurés et radiés qui ignorait leur proximité pondérale, il devenait difficile de faire circuler en même temps les deux monnaies. La réforme ne pouvait apparaître que défavorable aux espèces laurées et on imagine très bien qu'elle ait pu engendrer un phénomène de défiance. Ainsi, on s'expliquerait que la frappe régulière du bronze ait été suspendue dès le début du $3^{\mathrm{e}}$ consulat (262) du règne de l'usurpateur gaulois.

5 La mise en évidence à Sées d'une production par surmoulage de monnaies de bronze nous renseigne donc sur la façon dont était reçu ce métal entre 260 et 262 dans une cité des confins septentrionaux de l'Empire. Réduit sans doute à ce qui subsistait de l'époque antonine, il y circulait toujours activement - pour une part malheureusement impossible à évaluer. Mais, en surmoulant des bronzes du Haut-Empire à l'effigie radiée, le phénomène gagnait encore en originalité. Il répondait à la réforme de 260 , qui installait alors la monnaie radiée comme maître du marché. C'était finalement le moyen d'utiliser, avec profits, un stock d'émissions anciennes, dans un système en cours d'évolution.

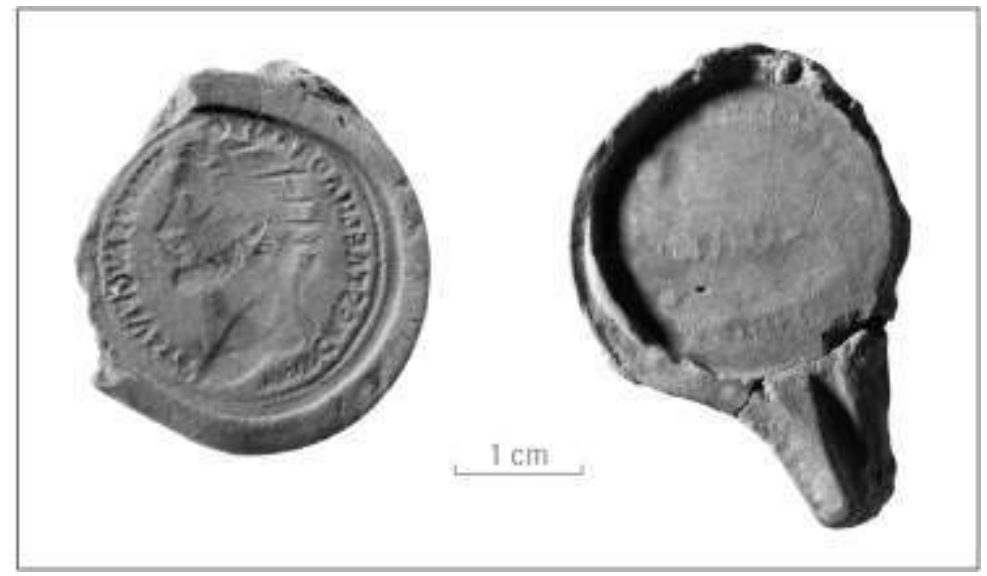

Fig 01

Moules en terre cuite du $\|^{\mathrm{e}} \mathrm{s}$.

Cliché : J.-C. Fossey (Craham) 
INDEX

Index géographique : Basse-Normandie, Orne (61), Sées

Mots-clés : moule, monnaie, bronze

operation Programme d'analyse (PAN)

Index chronologique : Gallo-romain

\section{AUTEURS}

\section{PIERRE-MARIE GUIHARD}

Craham 